\title{
Editor Note: Cardiovascular Diseases and Their Management
}

\section{Prithwish Banerjee*}

University Hospitals of Coventry and Wawickshire, UK

${ }^{*}$ Corresponding author: Prithwish Banerjee, Consultant Cardiologist, University Hospitals of Coventry and Wawickshire, UK, Tel: +442476965670; E-mail: Prithwish.Banerjee@uhcw.nhs.uk

Received date: May 16, 2016; Accepted date: May 20, 2016; Published date: May 25, 2016

Copyright: $\odot 2016$ Banerjee P, et al. This is an open-access article distributed under the terms of the Creative Commons Attribution License, which permits unrestricted use, distribution, and reproduction in any medium, provided the original author and source are credited.

Citation: Banerjee P (2016) Editor Note: Cardiovascular Diseases and Their Management. J Cardiovasc Dis Diagn 4: e112. doi: 10.4172/2329-9517.1000e112

\section{Editor Note}

Cardiovascular diseases are a leading cause of global mortality. It has been estimated that 23 million people will die due to cardiovascular diseases by 2030. Journal of Cardiovascular Diseases and Diagnosis is an open access peer reviewed international journal that publishes high quality scientific articles related to myocardial infarction/ischemic heart disease, aortic aneurysms, cardiomyopathies, congenital heart disease, myocarditis, cardiac arrhythmias, rheumatic heart disease, valvular heart disease, venous thrombosis etc., and their diagnosis.

In volume 4 , issue 3 , of the journal 5 articles were published discussing the risk factors of cardiovascular diseases and recent trends in cardiac surgery. These wide ranging articles from across the world make interesting reading and are contributory to our current knowledge on these areas.

Baranowski et al. [1] successfully simplified the protocol for transcatheter aortic valve implantation (TAVI) to reduce procedurerelated risk. They modified the standard protocol of implantation of balloon-expandable transcatheter aortic valve by simplifying the procedure to reduce the risk [1].

Mitra et al. studied the haemodynamic effects of spinal anesthesia for cesarean sections in patients with preeclampsia. They confirmed that subarachnoid block in preeclampsia patients was associated with better perioperative hemodynamic stability, less vasopressor consumption, less hypotension, and more gradual blood pressure change ps. They suggested that a pre-hydration strategy should follow in these patients [2].

Memon and co-authors evaluated the correlation of HbAlc levels in non-diabetic cardiovascular disease (CVD) patients with cardiovascular events. They found that in these patients the $\mathrm{HbAlc}$ level is highly correlated with the risk factors of CVD, such as dyslipidemia, hypertension and obesity [3].
The case presented by Barilla et al. highlighted the effectiveness of fondaparinux for treating heparin-induced thrombocytopenia (HIT) in cardiac surgery. They successfully treated three patients with fondaparinux despite significant limitations. They concluded that fondaparinux is a safe and effective option for treatment of HITrelated thromboembolic complications as the bleeding risk with it is low [4].

Fane et al. reported the first Moroccan case of meningoencephalitis and endocarditis in adults with a chronic alcoholism history and craniofacial trauma. Authors meticulously illustrated the severity of community acquired Klebsiella pneumoniae infection and the tendency of this bacterium to disseminate to multiple organs, especially in the presence of co morbid conditions [5].

\section{References}

1. Baranowski J, Nielsen NE, Ahn HC (2016) A simplified protocol for transcatheter aortic valve implantation that reduces procedure-related risk. J Cardiovasc Dis Diagn 4: 241.

2. Mitra M, Basu D, Ganguly T, Kar SK, Chaterjee S (2016) Comparison of the hemodynamic alterations in normotensive and preeclamptic pregnant woman posted for cesarean section under subarachnoid block. J Cardiovasc Dis Diagn 4: 242.

3. Memon AG, Soomro MK, Kolachi MA (2016) Correlation of glycated hemoglobin (HbAlc) with different cardiovascular risk factors in nondiabetic patients. J Cardiovasc Dis Diagn 4: 243.

4. Barilla D, Martinelli GL, Cotroneo A, Romano A, Iacopino P (2016) Thrombosis due to heparin-induced thrombocytopenia in cardiac surgery: Is fondaparinux an effective treatment?. J Cardiovasc Dis Diagn 4: 240.

5. Fane MEL, Dollo I, Sodqi M, Jebbar S, Nourredine K, et al. (2016) Septicaemia caused by community acquired klebsiella pneumonia complicated with endocarditis and meningoencephalitis: A case report. J Cardiovasc Dis Diagn 4: 244. 